\title{
Synthesis of BINOL-thiourea Derivatives
}

\section{Chen S, Zhang X, Yu Q, Lu W and Dai Z*}

Department of Medicinal Chemistry, School of Pharmacy, China Pharmaceutical University, China

*Corresponding author: Zhenya Dai, Department of Medicinal Chemistry, School of Pharmacy, China Pharmaceutical University, China

Received: May 19, 2017; Accepted: June 13, 2017; Published: June 20, 2017

\section{Introduction}

It is well documented that enantiopure R-BINOL-derivatives and thiourea-derivatives belong to privileged compounds which were widely applied in the field of asymmetric synthesis and organocatalysis [1]. Dual hydrogen bonding (DHB) catalyst have been received much attention in the field of enantioseletive synthesis [2]. Among the hydrogen-bonding complex, thiourea derivatives have been proved to be one of the most promising scaffolds, and much effort has been dedicated to find alternative motifs [3]. As a result, several scaffolds such as guandines, squaramides, were identified. On the other hand, Bronsted acid catalyst especially BINOL-derivatives has attracted much Attention [4]. Whereas thiourea and BIONLderivatives are well known as scaffolds and have been explored successfully as catalysts as well as ligand, however, combining the two units as a whole has scarecely been reported? The synthesis of phosphorylthiourea through the addition nucleophilic reaction of phosphorylisothiocycanide and substitude amines was published in 1987 [5,6]. Phorylthioureas have been used as insecticide, herbicide figicide plant growth regulator and so on $[7,8]$. Due to our current interests in the synthesis and applications of thiourea as well as R-BINOL-derivatives, we herein report a convenient and efficient protocol for the preparation of chiral organocatalyst I, II and III, which are promising reagents for further and diverse application.

\section{Experimental}

\section{General}

Melting points were determined in a capillary using a Melt Temp. II apparatus (Aldrich) or STUART SMP 30 and are uncorrected. ${ }^{1} \mathrm{H}$ NMR spectra were measured on a Bruker Avance III instrument (300MHZ). Chemical shifts (d) are given in ppm and coupling constants $\mathrm{J}$ in $\mathrm{Hz}$.

\section{Staring material}

All solvents and reagents are commercially available and used as received.

\section{Synthesis of compound B}

Procedure: Phosphorus oxychloride $(0.1 \mathrm{~mol})$ was added with stirring into a solution of (R)-(+)-1,1'-Bi-2-naphthol A $(0.1 \mathrm{~mol})$ in $\mathrm{CH}_{2} \mathrm{Cl}_{2}(5 \mathrm{ml})$, the reaction mixture was stirred at room temperature for 12 hours, then the formed hydrogen chloride and solvent were evaporated and a white solid was obtained.
The compound was used for next step without further purification (Yield: 88\%).

\section{Synthesis of compound C}

To a solution of $2(0.12 \mathrm{~mol})$ in acetonitrile $(20 \mathrm{~mL}), \mathrm{KSCN}$ $(0.25 \mathrm{~mol})$ was added gradually with stirring, and the mixture was stirred at $65^{\circ} \mathrm{C}$ for 10 hours, which was filtrated and extracted with dichloromethane $\left(15 \mathrm{~mL}^{\star} 2\right)$, the solvent was evaporated under reduced pressure to give a yellow liquid, which was used for the next step without further purification.

\section{The synthesis of I, II and III}

General procedure: To a mixture of $3(10 \mathrm{mmol})$ in chloroform $(30 \mathrm{~mL})$, a solution of aniline $(10 \mathrm{mmol})$ in chloroform $(10 \mathrm{~mL})$ was added drop wise with stirring. The mixture was refluxed until reaction completion was detected by thin-layer chromatography. The solvent was evaporated under the reduced pressure, the residue was diluted with ether $(10 \mathrm{~mL})$ and cooled in ice-water bath, the crude product was crystallized with DMF- $\mathrm{H}_{2} \mathrm{O}$ to give the target compound.

Compound I: White solid, mp: $152-154^{\circ} \mathrm{C}$, yield: $64 \%$.

${ }^{1} \mathrm{H}-\mathrm{NMR}\left(\mathrm{CDCl}_{3}, 300 \mathrm{MHZ}\right): 8.5812(\mathrm{~m}, 1 \mathrm{H}): 8.5525-8.0446(\mathrm{~m}$, $1 \mathrm{H}), 7.9772-7.8824(\mathrm{~m}, 4 \mathrm{H}): 7.8139-7.7832(\mathrm{~m}, 1 \mathrm{H}), 7.7232-7.6962$ (m, 1H), 7.5431-7.5145 (m, 3H), 7.3224-7.2597 (m, 4H), 6.7526$6.7230(\mathrm{~m}, 1 \mathrm{H}), 6.3390(\mathrm{~s}, 1 \mathrm{H}), 2.5864-2.5562(\mathrm{~m}, 1 \mathrm{H}), 2.3828-2.3453$

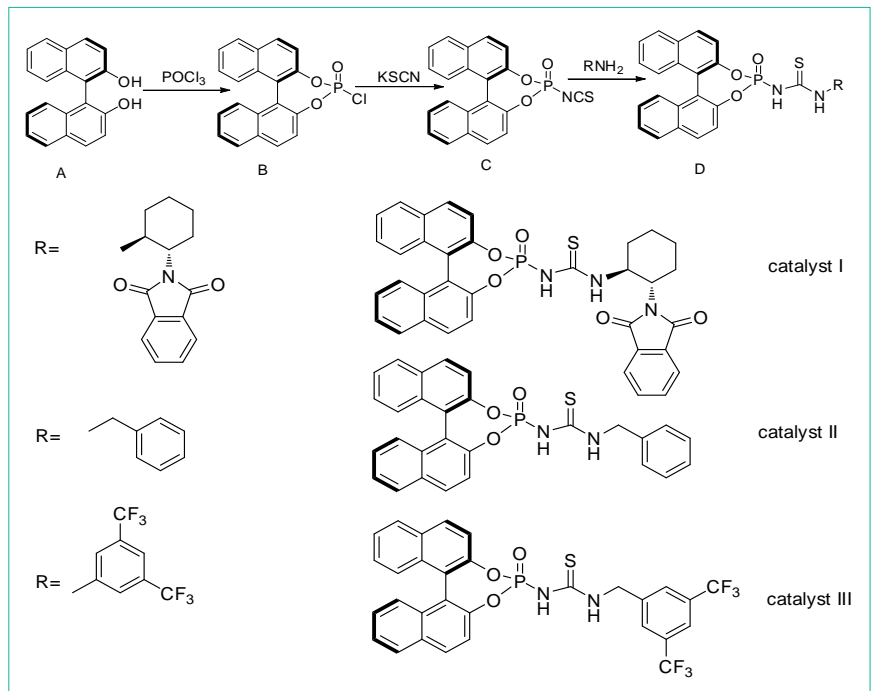

Figure 1: Experiment. 
$(\mathrm{m}, 1 \mathrm{H}), 1.8722-1.8195(\mathrm{~m}, 3 \mathrm{H}), 1.4284-1.2335(\mathrm{~m}, 4 \mathrm{H}), 0.9577-$ $0.8556(\mathrm{~m}, 1 \mathrm{H})$

HRMS: [M+Na]: 656.1; found: 656.4

Compound II: Yellow solid, mp: $178-181^{\circ} \mathrm{C}$, yield: $70 \%$.

${ }^{1} \mathrm{H}-\mathrm{NMR}\left(\mathrm{CDCl}_{3}, 300 \mathrm{MHZ}\right): 8.5812-8.5525(\mathrm{~m}, 1 \mathrm{H}), 8.6446$ $8.0152(\mathrm{~s}, 1 \mathrm{H}) ; 7.9772-7.8824(\mathrm{~m}, 4 \mathrm{H}), 7.8139-7.7842(\mathrm{~m}, 1 \mathrm{H})$, 7.7232-7.7135 (m, 2H), 7.5431-7.5145 (m, 3H). 7.3226-7.3121 (m, $4 \mathrm{H}) ; 6.7526-6.7230(\mathrm{~d}, 1 \mathrm{H}) ; 6.3390(\mathrm{~s}, 1 \mathrm{H}) ; 2.5864-2.5562(\mathrm{~d}, 1 \mathrm{H})$; 2.3828-2.3453 (m, 1H); 2.0407 (s, 1H).

HRMS: [M+Na]: 519.4; found: 519.1

Compound III: Yellow solid, mp: $155-156^{\circ} \mathrm{C}$, yield\%: $63 \%$.

${ }^{1} \mathrm{H}-\mathrm{NMR}\left(\mathrm{CDCl}_{3}, 300 \mathrm{MHZ}\right): 10.9985$ (s, 1H), $\left.8.2316 \mathrm{~s}, 2 \mathrm{H}\right)$, 8.1535-8.1358 (m, 1H), 8.0182-7.9923 (m, 2H), $7.7506(\mathrm{~s}, 1 \mathrm{H})$, 7.6158-7.5335 (m, 4H), 7.4101-7.3632 (m, 4H), 6.8569 (s, 1H).

HRMS: [M+Na]: 641.5 ; found: 641.1

\section{Results and Discussion}

A typical procedure for the synthesis of phosphorylisothiocycanide is the treatment of the phosphorus oxychloride with KSCN [9]. Then BINOL-thiourea derivatives were easily achieved through the reaction between phosphorylisothiocycanide and amines. Herein, catalyst I, II and III were prepared in this way with moderate yield and their structures were confirmed by ${ }^{1} \mathrm{HNMR}$ and MS

\section{Conclusion}

Herein we have reported that BINOL-derivatives can be prepared conveniently by using phosphorylisothiocycanide with amines. And their applications in asymmetric organocatalysis were still under way in our group.

\section{References}

1. List B. Emil Knoevenagel and the Roots of Aminocatalysis ${ }^{\dagger}$. Angew. chem Int. Ed. 2010; 49: 1730-1734.

2. Auvil TJ, Schafer AG, Mattson AE. Design Strategies for Enhanced HydrogenBond Donor Catalysts. Eur. J. Org. chem. 2014; 2014: 2633-2646.

3. Okino T, Hoashi Y, Takemoto YJ. Enantioselective Michael Reaction of Malonates to Nitroolefins Catalyzed by Bifunctional Organocatalysts. Am. chem. Soc. 2003; 125: 12672-12673.

4. (a) Kobayashi Y, Taniguchi Y, Hayama N, Inokuma T, Takemoto Y. Angew. A Powerful Hydrogen-Bond-Donating Organocatalyst for the Enantioselective Intramolecular Oxa-Michael Reaction of $\alpha, \beta$-Unsaturated Amides and Esters. Chem. Int. Ed. 2013; 11114; (b) Isik M, Unver MY, Tanyeli CJ. Modularly Evolved 2-AminoDMAP/Squaramides as Highly Active Bifunctional Organocatalysts in Michael Addition. Org. Chem. 2015; 80: 828.

5. Liu ZJ, Hu HB, Zhang JL. Journal of central china university. 1987; 21 : 3.

6. Hu SX, Jiang H, Wang P. Chemical journal of Chinese university. 1994; 15: 11.

7. David P. Clifford. Pestie. Sei. 1988; 23: 297 305.

8. Yang HZ, Wu H, zhang HF. Chemical journal of Chinese university. 1001; 12: $144-148$

9. Kuang MY, Li ZH. Studies on Synthesis and Biological Activities of phosphorylthiourea derivatives. 2004.
Austin J Anal Pharm Chem - Volume 4 Issue 2 - 2017 ISSN : 2381-8913 | www.austinpublishing group.com Dai et al. () All rights are reserved
Citation: Chen S, Zhang X, Yu Q, Lu W and Dai Z. Synthesis of BINOL-thiourea Derivatives. Austin J Anal Pharm Chem. 2017; 4(2): 1086 